\title{
Las formas del recuerdo. La memoria
}

narrativa

\author{
Jorge Mendoza García \\ Universidad Autónoma de Tlaxcala \\ jorgeuk@correo.unam.mx
}

\section{Resumen}

La memoria tiene una estructura narrativa. Sus contenidos, formas y maneras de expresión así lo ponen de manifiesto. Retomando planteamientos de los fundadores de la perspectiva de la memoria colectiva, Halbwachs, Blondel, Bartlett y Vygotsky, y reflexionando desde los postulados de Bruner, el presente trabajo argumenta que la memoria, incluso la denominada individual, se construye sobre la base de narraciones que constituyen formas de discursos y modos de organizar experiencias, por ejemplo las pasadas, que son culturalmente dotados de significado, y que para ser inteligibles a la persona, grupo, sociedad o colectividad a quien se presentan hay que expresarla en relatos lógicos que muestren la verosimilitud de lo que se está recordando o relatando. Ciertamente, en la vida cotidiana encontramos cantidad de narraciones sobre las experiencias colectivas, encontramos "narradores de historias", y como ocurre en la literatura no sólo vale lo que se cuenta sino cómo se cuenta. Así como hay convenciones de ideas sobre la realidad, las hay también para las narrativas: existen modelos narrativos que hacen más verosímil una narración que otra. Tales narraciones dotan de sentido al mundo. Las narraciones, asimismo, devienen marcos sociales de la memoria, como el tiempo y espacio de los que habló Halbwachs, la modalidad narrativa es un marco, una manera de enmarcar la experiencia, y lo que no se estructura de forma narrativa se pierde de la memoria. A esos marcos Bartlett los denominó esquemas, que son delineados por instituciones, costumbres y grupos, que dictan cómo hay que presentar los eventos pasados, es decir, cómo hay que narrarlos, y en tanto relatos, éstos dan forma a las realidades que crean y eso opera para las experiencias pasadas que el grupo guarda. Palabras clave: Memoria colectiva, narrativa, relato, significado, sentido, marcos sociales, esquemas

Narrar es "relatar", "contar", "referir", informar acerca de algo, como antaño se hacía, como la tradición oral dicta; relatar es informar acerca de algo (Gómez de Silva, 1985), y ese algo debe tener algún sentido, cierto significado para quien narra y para quien escucha o lee, porque esa es la cualidad de la memoria: guardar y dar cuenta de lo significativo de la vida, de lo que vale la pena mantener para luego comunicar y que alguien más lo entienda. En efecto, el sentido alude al entendimiento, a la razón, a una especie de explicación, pero no la cientificista, sino la de la cotidianidad, la que la gente en la vida ordinaria maneja y siente, de ahí que se hable de finalidades, de significaciones y de interpretaciones, porque exactamente el sentido alude a una dirección. En suma, el sentido se sostiene sobre la base de entender algo, de encontrarle razón, de otorgarle significado, de brindarle importancia a algo, atributos éstos de la memoria. 
Y resulta que el sentido, el significado de los eventos, se construye culturalmente. Por estar inmerso en la cultura, "el significado adopta una forma que es pública y comunitaria en lugar de privada y autista" (Bruner, 1990, p. 47). La cultura deposita la actuación humana en un marco interpretativo dotándola de significado, lo que se da a partir de la implementación o imposición de "patrones inherentes a los sistemas simbólicos de la cultura: sus modalidades de lenguaje y discurso, las formas de explicación lógica y narrativa, y los patrones de vida comunitaria mutuamente interdependientes" (p. 48). Luego entonces, el sentido que la gente le otorga a sus actos y sus experiencias se encuentra en las arenas sociales, y en la manera como se narran los sucesos de la realidad y la forma como se construyen. $Y$ el relato permite acceder a tales sentidos.

\section{Narrativa como marco social de la memoria}

La interrogante que se plantea en tal situación es: “¿Qué se gana y qué se pierde, cuando los seres humanos dan sentido al mundo contando historias sobre el mismo usando el modo narrativo de construir la realidad?" (Bruner, 1997, p. 149). La narrativa, puede entenderse, es una reflexión sobre la condición humana (Bruner, 2002): "nuestra experiencia de los asuntos humanos viene a tomar la forma de las narraciones que usamos para contar cosas sobre ellos" (Bruner, 1997, p. 152) ${ }^{1}$. Cuestión que el propio Aristóteles advertía cuando hablaba de las formas literarias que "imitan" la vida ${ }^{2}$.

${ }^{1}$ Sobre el surgimiento de la narrativa, Bruner (2002) señala que inicia con las comunidades primitivas y los ritos de siembra, cosecha y la medicina; una participación colectiva puesta en escena (tipo rito de Thor, el del mito, como narra Gaarder en El mundo de Sofía), pues había que representarlos para mantener las consecuencias, por ejemplo que lloviera, de sus prácticas. Así se representaban y se imitaban episodios pasados, y se comunicaban, se transmitían a otras generaciones. Se pasa de esta manera al cuento, a la declamación mediante el lenguaje como "referencia a distancia", sin necesidad de que los objetos estén presentes; hay una arbitrariedad de la referencia, en cuanto al uso del lenguaje, por eso los signos no necesariamente se parecen a su referente, como sí ocurre con la pintura. Al paso del tiempo son tres cuestiones las que posibilitan la narrativa: a) la eficacia a distancia -hablar de objetos sin tenerlos físicamente-, b) la arbitrariedad -los signos pueden no parecerse a lo referido-, y c) la gramática de casos -cierta sintáxis-. Así "el sacerdote-actor ritual puede formular con sus palabras un buen augurio para la siembra, así como el cronista que relata un combate con las tribus vecinas o el padre que habla a su hijo de ancestros a imitar; y todo esto puede ser dicho, años más tarde, en cualquier sitio, junto al hogar, a una sola persona o a muchas, o inclusive a uno mismo" (p. 135).

${ }^{2}$ Con los medievales no hubo problema alguno en torno a la narrativa, fue con el renacimiento y el iluminismo que se presentaron algunos inconvenientes. Fue un folklorista ruso, Vladimir Propp, después de la Revolución Soviética, quien revivió el interés por la narrativa; otro, Kenneth Burke hablaba de la narrativa como una forma de afrontar las dificultades humanas; después, por el cientificismo, se dejó en manos de los literatos, pero uno que otro cientista social, el lingüista Lavov por ejemplo, se mantuvo con esa forma de tratar la realidad social al señalar que era un medio para comprender lo poco grato. Después, los historiadores renovarían el trato con ella, como resultado de la "desilusión provocada por la historiografía" y como respuesta al sufrimiento y desconsuelo en que se encuentran sumidas las sociedades (Bruner, 2002). 
Ciertamente, los eventos construyen discursos, o los posibilitan pero, asimismo, hay discursos que permiten la constitución de acontecimientos, y les otorgan sentido, como certeramente lo ha expresado Ricoeur.

La memoria colectiva, como lo enunciaban Halbwachs y Blondel es un proceso social de reconstrucción de un pasado vivido y/o significado por un grupo o sociedad, que se contiene en marcos sociales, como el tiempo y el espacio, y como el lenguaje, pero también se sostiene por significados, y éstos se encuentran en la cultura. $\mathrm{Si}$, porque a decir de estos autores la memoria mantendrá aquello que considere significativo, con sentido; no ocurre a la manera de Funes el memorioso, de Borges, que retenía todo lo que veía o experimentaba. Ese no es el caso de la memoria, pues en ella se contiene lo que valga la pena guardar, aquello que cobra sentido ${ }^{3}$.

Estos marcos, en otro estudioso de la memoria llevan la denominación de esquemas ${ }^{4}$. En la noción de Bartlett (1932) los "esquemas de memoria" se encuentran bajo el control de una "actitud afectiva". Así, una tendencia conflictiva que amenace el equilibrio, individual o social, es capaz de desestabilizar la propia organización de la memoria. Por eso este estudioso señalaba que cuando intentamos recordar algo, lo primero que llega no es el recuerdo como tal, sino un "afecto" o una "actitud cargada". Acto seguido, una manera de relatar, esto es, una narración. Por eso quizá es que Bruner (1990, p. 68) advierte que: "la experiencia y la memoria del mundo social están fuertemente estructuradas no sólo por concepciones profundamente internalizadas y narrativizadas de la psicología popular sino también por las instituciones históricamente enraizadas que una cultura elabora para apoyarlas e inculcarlas".

Ciertamente, en Halbwachs (1925) los marcos empíricos son fechas y lugares, y en Bartlett (1932) son esquemas, y en Bruner (1990) es la narrativa, las formas de narrar. Ello porque la modalidad narrativa es un marco, una manera de enmarcar la experiencia, y de esta manera "lo que no se estructura de forma narrativa se pierde en la memoria" (p. 66).

En la vida ordinaria la gente no enfrenta el mundo acontecimiento por acontecimiento, como tampoco se lee palabra por palabra o frase por frase. Tanto acontecimientos como frases se enmarcan en algo

3 "La diferencia esencial entre las aproximaciones cognitivas y discursivas a la narrativa (o historias) es que las cognitivas las tratan como expresiones de cómo entiende la gente las cosas, mientras que las discursivas las tratan como producciones orientadas a la interacción. En el discurso, 'la manera en que la gente entiende las cosas' se disuelven las prácticas discursivas" (Edwards, citado en Vázquez, 2001, p. 92). Por su parte, Bartlett ha señalado: "tanto la forma como el contenido del recuerdo suelen estar determinados primordialmente por las influencias sociales" (1932, p. 316).

${ }^{4}$ Este autor asevera: "Todo grupo social se ve organizado y mantenido por alguna tendencia psicológica específica o por un grupo de éstas, que confieren al grupo un sesgo en su relación con las circunstancias externas. Este sesgo construye las características especiales y duraderas de la cultura del grupo [y esto] determina inmediatamente lo que el individuo va a observar en su ambiente y las conexiones que establecerá entre su vida pasada y esta respuesta directa. Este efecto del sesgo se produce especialmente de dos maneras. En primer lugar, proporcionando esas condiciones de interés, excitación y emoción que favorecen el desarrollo de imágenes específicas; y, en segundo lugar, proporcionando un marco permanente de instituciones y costumbres que actúa como base esquemática para la memoria constructiva" (Bartlett, 1932, p. 255). 
más amplio, en estructuras mayores, esquemas, planes, marcos de la memoria; desde esta perspectiva narrativa, tales estructuras mayores "proporcionan un contexto interpretativo para los componentes que abarcan". Por eso señala Bruner que sólo se puede "comprender los principios que rigen la interpretación y elaboración de los significados, en la medida en que seamos capaces de especificar la estructura y coherencia de los contextos más amplios en que se crean y transmiten significados específicos" (1990, p. 73). Y esos son los marcos sociales; ya lo había expresado Blondel: "la experiencia pasada, como la presente, se comprende a través de los cuadros y de las nociones que nos ha provisto la colectividad" (1928, p. 148). "Evocamos al recuerdo sólo para llenar el marco y prácticamente no tendríamos el recuerdo si no tuviéramos el marco para llenar" (p. 151). Y el marco lo recibimos, no mediante una cuestión personal, sino como una experiencia colectiva. Sean fechas o lugares los marcos, hay que expresarlos, y es que evocar un espacio es evocar un tiempo y un grupo o colectividad, y es hacerlo con un lenguaje, con una cierta estructura, con una narrativa acorde al propio grupo para hacerla entendible. Dichos marco sociales aseguran la fijeza y coherencia de los recuerdos en ellos inscritos, y regulan de manera sistemática el empleo que de ellos hacemos. Asimismo, los marcos le "proporcionan estabilidad y persistencia" a la memoria.

\section{Narrativa y memoria}

Existen acuerdos narrativos que "modelan las experiencias", para que, por caso, se indique cómo hay que vivenciarlas, para darle un sentido al mundo. Estas formas de discurso son un modo de organizar también la experiencia pasada. En esta forma organizativa se encuentran, entre otras cuestiones, una composición hermenéutica: los sucesos que acontecieron tienen más de una interpretación. Porque múltiples son las memorias, tantas como grupos hayan significado un evento (Halbwachs, 1950; Fernández Christlieb, 1994). No hay versión verdadera, pues sus significados y lo que representan para diversos grupos son múltiples. "El objetivo del análisis hermenéutico es aportar una explicación convincente y no contradictoria de lo que significa un relato, una lectura que se atenga a los detalles particulares que la constituyen" (Bruner, 1997, p. 156) ${ }^{5}$. Se encuentra, por otra parte, la negociabilidad inherente: las narraciones y argumentos se acompañan de credibilidad. Se aceptan, de entrada, ciertos elementos de los relatos, el resto puede estar sujeto a negociación, pero se escuchan las partes, y no se requiere de litigaciones ni mediaciones: "Puede ser esta capacidad para considerar múltiples construcciones narrativas la que aporte la flexibilidad que se necesita para la coherencia de

${ }^{5}$ Se recurre al círculo hermenéutico: la "adecuación" de una cierta lectura de algún evento es en referencia, más que al mundo observable, a otras lecturas posibles. Charles Taylor lo expone así: "Estamos intentando establecer una lectura del texto completo y para ello apelamos a lecturas de sus expresiones parciales; y siendo así que estamos tratando del significado, de dar sentido, allá donde las expresiones sólo tienen sentido o no en relación con otras, las lecturas de unas expresiones parciales dependen de las de otras y en último término del todo" (en Bruner, 1997, pp. 156-157). Los significados de las partes dependen, en buena medida, del relato total, y éste a su vez para formarse depende de las partes. Eso mismo ocurre con el autor-lector: el autor crea textos que crean a su vez audiencias que crean textos propios del escrito original. El lector se transforma en coautor de la obra. Y así el lector busca un "motivo" en la escritura del autor, desapareciendo la objetividad que se creía tenía el autor. Hilary Putnam ha expresado: "Todo narrador tiene un punto de vista y tenemos un derecho inalienable a cuestionarlo" (en p. 158). 
la vida cultural" (p. 163). Está, asimismo, la extensibilidad de memoria de la narración. La realidad de un grupo, persona o colectividad no se restringe a un evento, hay diversos, y estos devienen hilo de continuidad que tratan de darle coherencia al pasado, convirtiéndose en una memoria. Por eso podemos movernos hacia atrás o hacia adelante en el tiempo. $Y$ es que, para ello hay situaciones o acontecimientos clave, "puntos de inflexión", puntos de apoyo, como suelen ser los marcos o los artefactos de la memoria como las fotografías de la familia o las placas conmemorativas en lugares memorables.

Esta perspectiva que atraviesa a la memoria colectiva, opera de igual manera para la historia, sólo que los historiadores duros no lo reconocen, de ahí la insistencia de Halbwachs de desmarcarse de la historia positivista y oficial y proponer otros derroteros para la memoria ${ }^{6}$. Las narraciones sobre acontecimientos significativos del pasado, si quieren ser buenas o atractivas en ciertas ocasiones recurren a lo incierto, a lo ambiguo, a las múltiples interpretaciones, a las lecturas alternativas, y para ello han de considerar algunas cuestiones: i) resulta más fácil identificarse con ellas si nos sientan bien y por ello las aceptamos; en cambio, si nos incomodan las podemos rechazar: "una memoria es experiencia viva", ha dicho el escritor Eduardo Galeano, de ahí que una buena narración como la que él se propone consista en "hacerlo de tal manera que el lector sienta que lo ocurrido vuelve a ocurrir cuando el autor lo cuenta" (1986, p. xix), lo cual, en verdad logra en su trilogía Memoria de fuego; ii) una memoria es la memoria de alguien, de un grupo por ejemplo, y tienen una voz narrativa, de tal suerte que lo que se narra se hace mediante una serie de premisas grupales o personales. "Carecen del carácter de 'muerte súbita' de las exposiciones construidas de forma objetiva, en las que las cosas se reflejan 'como son'. Cuando queremos llevar un relato acerca de algo al dominio de los significados negociados, decimos, irónicamente, que ha sido un 'buen cuento' o una 'buena historia'. Las historias, por consiguiente, son instrumentos especialmente indicados para la negociación social. Y su status, aún cuando se consideren historias 'veraces', permanece siempre en un terreno a medio camino entre lo real y lo imaginario" (Bruner, 1990, p. 65) ${ }^{7}$.

Puede advertirse que pertenecer a una cultura es encontrarse inmerso en un sinnúmero de relatos interconectados en torno al pasado, aunque no todos ellos establezcan un acuerdo, un consenso. Pueden presentarse los disensos, discontinuidades, desavenencias. De esta forma, puede ocurrir que se produzca una ruptura en una cultura, en una relación (por ejemplo, la familia o la escuela), lo cual puede deberse i) a una fuerte discrepancia entre lo que es canónico y lo que es ordinario; entre lo excepcional y lo divergente; ii) puede, asimismo, ser consecuencia de la excesiva especialización narrativa, ya que en ocasiones se vuelven tan de motivación egoístas o ideologizadas que entonces

${ }^{6}$ La misma historia, lo ha señalado Todorov (2000, p. 169), no llega como dato (por más que así se le intente mostrar) sino como relato, como narración. "Ni siquiera la historiografía... puede sustraerse a la perspectiva que domina su exposición narrativa" (Bruner, 2002, p. 41).

${ }^{7}$ Existen ciertos principios que pueden advertirse como constantes en las narraciones, sean ficciones o asuntos del recuerdo: así, por caso, i) hay un reparto de personajes, libres de actuación con mente propia; ii) tienen expectativas reconocibles; iii) el relato inicia con la alteración de un cierto orden, y cuando "algo está alterado" hay algo que narrar; iv) "la acción del relato describe los intentos de superar o llegar a una conciliación con la infracción imprevista y sus consecuencias; v) al final hay un resultado, algún tipo de solución"; asimismo, vi) "se precisa de un narrador, un sujeto que cuenta y un objeto que es contado" (Bruner, 2002, p. 34). 
la interpretación es suplida por la desconfianza ( $y$ en donde no hay credibilidad simplemente no hay diálogo) y lo "sucedido", el acontecimiento narrado, se mira como "fabricado", que puede ser el caso de ciertas formas de Historia (Galeano, 1986). La forma extrema de esto se experimentó en los países del Este europeo en el pasado siglo XX, y sus narradores, novelistas, dan cuenta de ello (por ejemplo Milan Kundera y Danilo Kis); o como también ocurrió con las dictaduras latinoamericanas en los setenta y ochenta, y también sus literatos dan cuenta de ello (Eduardo Galeano, Miguel Bonaso, Isabel Allende, son buenos ejemplos); otro caso ilustrativo es el 68 mexicano: durante años, décadas, la narrativa oficial en torno al movimiento estudiantil fue de descalificación, en todo momento habló de conjura comunista internacional en contra del gobierno, narrativa poco verosímil y pobre; por el otro lado, los estudiantes exponían cada vez que podían su versión: la lucha por libertades democráticas y que fueron víctimas de un gobierno represor: ahora, a 35 años de distancia, se está aclarando lo que sucedió; iii) una tercera ruptura se puede presentar por el fuerte empobrecimiento de los recursos narrativos, tal es el caso de los habitantes de los barrios en extrema pobreza, los pueblos hambrientos, los azotados por constantes catástrofes, entre otros: "No es que se haya perdido totalmente la capacidad para narrar la propia experiencia, sino que el 'peor de los escenarios' se ha vuelto tan dominante en la vida diaria que las variaciones ya no parecen posibles" (Bruner, 1990, p. $98)^{8}$. La narrativa, en todo caso, se ubica en el ámbito de la memoria y no en el del sueño ni en el de la fantasía (White, 1987, p. 25).

Por otro lado, los relatos son narrados en todo momento desde alguna perspectiva en particular. Las personas cuando hablan, también van determinando qué consideran "memorable" y qué no (Vázquez, 2001): "cuando las personas hacemos memoria, mediante nuestro discurso sostenemos, reproducimos, extendemos, engendramos, alteramos y transformamos nuestras relaciones. Es decir, la memoria de cada persona cambia en la relación y cambia [también] las relaciones" (p. 115).

En última instancia, la memoria es narrativa en un doble sentido, como relato de progresión de acontecimientos en el hilo del tiempo, y como conformación de una trama (con actores, escenarios y acciones), y de ser verosímil, no verdadero, es aceptado en la medida en que se adecue, o acerque, a criterios validados socialmente: existen formas convencionales de cómo narrar o dar cuenta de los eventos. Y lo que se narra debe tener sentido. Así, pueden encontrarse muchas narraciones, pero no todas son aceptadas como validas. Además, se otorga significado a las vivencias presentadas que

${ }^{8}$ Robert Darnton (1984) recupera un acontecimiento que realiza un grupo de trabajadores del parís de la década de 1730, en La gran matanza de gatos. Entre los felinos se encontraba la consentida de la esposa del patrón. Los trabajadores tejen todo un acto simbólico y real en la ejecución de los animales, una especie de revancha por el trato que reciben: se da cuenta de que "los obreros encontraban divertida la matanza porque les ofrecía una manera de vengarse del burgués. Al estimularlo con los maullidos, lo provocaron para que autorizara la matanza; después usaron ésta para hacerle un juicio simbólico por su manejo injusto del taller. También usaron esto como una cacería de brujas, lo que les dio una excusa para matar al demonio familiar de la patrona y para insinuar que era bruja. Finalmente, transformaron esto en una encerrada, que sirvió como medio para insultar sexualmente a la patrona y burlarse del patrón por cornudo. El burgués resultó un blanco excelente para la broma. No sólo se convirtió en la víctima de algo que había iniciado, sino que no se dio cuenta de que lo habían usado. Los hombres habían realizado una agresión simbólica, del tipo más íntimo, contra la patrona, pero él no se dio cuenta. Era demasiado tonto, un típico cornudo. Los impresores se burlaron de él, con magnifico estilo boccacciano, y salieron bien librados" (p. 96). 
resultan relevantes; Ricoeur lo pone en estos términos: "el tiempo se hace tiempo humano en cuanto se articula de modo narrativo; a su vez, la narración es significativa en la medida en que describe los rasgos de la experiencia temporal" (en Vázquez, 2001, p. 109). Asimismo, la narración posibilita de alguna forma que la memoria se integre en la "práctica constructiva humana y las personas adquieran sentido y protagonismo al incluirse en el relato" (p. 109), y de no encontrase incluidos en la narración, al menos construirlas y manifestarlas. Eso es lo que propone el psicólogo ruso Vygotsky (1930; 1931), que en sus trabajos con infantes encontró que, al paso del tiempo, los niños interiorizaban los signos externos (fichas o palabras escritas) a signos internos (pensamientos, por caso), los cuales terminaban por mediar la memoria. Pero no sólo eso, sino que resaltó la manera como los infantes recordaban. Así, ante la palabra "muerte" el niño tomaba una carta con la imagen de un camello, y al preguntársele el por qué, explicaba que el camello se encontraba en un desierto y el jinete moría de sed: para recordar construían pequeños relatos. Esto, entre otras cosas, llevó a Vygotsky a proponer que la "estructura de la memoria mediatizada debe verse como narrativa, ofreciendo sus resultados en virtud del significado de los factores mediacionales empleados... Recordamos construyendo narraciones que requieren la evocación de hechos pasados para su conclusión inteligible" (en Bakhurst, 1990, p. 229).

\section{Construyendo y narrando la memoria: los testimonios}

El testimonio es de alta importancia en los asuntos de la vida cotidiana; es algo que reincluye la narrativa: al preguntar a una persona quién es, nos contará una pequeña historia (en el sentido de relato). Ahí está el testimonio. El testimonio es una huella, el relato de que algo sucedió, existió (Ricoeur, 1999). Cuando se dice que algo sucedió se plantean tres cuestiones: i) la presencia en el suceso del que narra; ii) se solicita credibilidad sobre lo que narra; se solicita confianza, y entonces la memoria se comparte: "el recuerdo de uno es ofrecido al otro, y el otro lo recibe"; iii) si no hay credibilidad en lo narrado, se puede recurrir a otro testimonio o narración. Es de esta forma que el testimonio "traslada las cosas vistas a las cosas dichas, a las cosas colocadas bajo la confianza que el uno tiene en la palabra del otro" (p. 27). En sentido estricto, el testimonio incorpora la memoria en el discurso, en el relato, en las narrativas.

El testimonio se convierte en puente entre el archivo y la memoria, y ello porque el "testigo, vio, escuchó o experimentó", por lo que quizá fue afectado o marcado, "alcanzado por el acontecimiento". La memoria se desprende de este testimonio, de esta experiencia, de este relato vivo, como ocurre exactamente con las memorias colectivas de los grupos: se alimentan de lo vivido, de las personas que en ellas han participado o significado ${ }^{9}$. El testimonio es también un tipo de monumento, el escrito,

\footnotetext{
${ }^{9}$ Los eventos dejan marcas, pero esa no es la memoria; la memoria va resignificando a la marca, a la huella cada vez que recurre a ella. En cambio, cuando el relato se archiva, se documenta, se almacena, es fácilmente atrapable por el poder y por cualquier mal intención que se presente (Calveiro, 2002). El problema del archivo es que queda fijado, ya dicho, sin posibilidad de reconstruirse a sí mismo, no como el relato o la narrativa, queda como relato fijo. En la historia lo que interesa es la fidelidad del testimonio, no su interpretación o manera de reconstruir, importa su fijeza, mientras que en la memoria se retoma la interpretación, la viveza del relato y el significado que éste tiene.
} 
de cuya lectura (o escucha) se forman ideas sobre determinados acontecimientos o episodios de una colectividad, y luego se vuelven a comunicar (Riegl, 1903). En otros casos, sin embargo, el testimonio es ruptura de convenciones y de armonías, o supuestas concordias, como sucede con los relatos de aquellos que vivieron tragedias, de lo cual está lleno Latinoamérica. En tal caso, al recuperar la pluralidad de las memorias, mediante lo experimentado, y al detenerse en la riqueza y amplitud de lo no generalizable, el testimonio "es capaz de romper con el relato consistente, con la explicación fácil y unidimensional, con la pretendida aprehensión de lo inconcebible, reclamando un nuevo ángulo cada vez, mostrando la fisura, señalando la contradicción que reclaman otra y otra y otra mirada posible y que nos imponen actualizaciones interminables" (Calveiro, 2001, p. 22).

Dice Pilar Calveiro que el testimonio como herramienta "se hace cargo de una deuda contraída -con el pasado y con el futuro- que liga al sobreviviente con los muertos y con los vivos" (p. 21), que lo lleva a recordar, pero sin la pretendida literalidad y repetición mecanicista, sino con fines reconstructivos porque es fiel, y fiel etimológicamente es "digno de confianza", de fiar, de confiar (Goméz de Silva, 1985). Por su parte, el poeta Juan Gelman (2002) advierte que el testimonio exige ser escrito en primera persona. Cuestión de preguntarle a varios de los exiliados latinoamericanos que tuvieron que huir de los militares para salvar la vida; más de uno, según muestran varios de sus trabajos, comunican nostalgia, melancolía, por ese pasado "glorioso" en el que vivieron, en especial los tiempos de la clandestinidad, y que no ven en el presente, y menos aún en el futuro; nada bueno, nada que posibilite lo que buscaron con sus batallas tiempo atrás: el futuro se les va de las manos. Anhelan el retorno al momento originario, ese punto de partida donde aún había esperanza. De ahí que espeten continuamente: "iSalud!, por los viejos tiempos" (Garrido, 1996, p. 20).

\section{Memoria narrativa que comunica}

La capacidad que tienen las colectividades para narrar sus experiencias, es "un instrumento para proporcionar significados que domina gran parte de la vida en una cultura, desde los soliloquios a la hora de dormir hasta los testimonios de los testigos en un sistema legal" (Bruner, 1990, pp. 98-99). En más de un caso, narración y oralidad confluyen para reconstruir experiencias pasadas, y así reordenan el proceso social de una colectividad. $\mathrm{Y}$ es eso justamente lo que le da vigencia a anteriores prácticas, saberes y procederes. La oralidad fue el primer camino que siguió la comunicación del pasado. Un rasgo a destacar en el caso de la memora indígena es esa cualidad de comunicarse de manera hablada de una generación a otra, de un grupo a otro, de una persona a otra: "esta naturaleza de la memoria indígena explica su tendencia a la repetición, su obsesión por contar una y otra vez la misma historia para conjurar el riesgo del olvido" (Florescano, 1987, p. 255).

No obstante, la oralidad no es el único mecanismo, pues la memoria se ha de comunicar de diversas formas, por ejemplo a través de lo que conserva, como ciertos textos o artefactos (Vygotsky, 1930; 1931), y otros mecanismos que las sociedades crean para esa tarea: "Con el tiempo, el compartir historias comunes crea una comunidad de interpretación" (Bruner, 2002, p. 45), lo cual se vuelve necesario, puesto que en la comunicación debe haber una cierta acogida, un recibimiento, un oído atento, para que la memoria pueda legarse, pues de lo contrario sólo se informaría y no necesariamente se entendería o comprendería, que fue lo que le ocurrió a Primo Levi (1958), sobreviviente de los campos de exterminio nazi, quien narró sus experiencias en esos sitios en el libro 
Si esto es un hombre, libro que no tuvo buena recepción: no gozó de notoriedad ni de comprensión ${ }^{10}$. Quizá por eso es que otro sobreviviente de esos campos, y también alumno de Halbwachs, Jorge Semprún, advierte que la comprensión esencial de las experiencias de las tragedias, "sólo lo es mediante la escritura literaria", un cierto tipo de narrativa $(1995, \text { p. 141) })^{11}$. Por ello, tal vez, se ha dicho que se escribe porque se quiere comunicar (Corcuera, 1997) ${ }^{12}$. Precisamente, esa es una etimología de la narrativa: "dar a conocer", "hacer saber" (Gómez de Silva, 1985), pero también hace referencia a "conocedor", "familiarizado con" (White, 1987).

La vida colectiva tiene una cualidad que permite la organización y la comunicación de experiencias: la forma narrativa (Bruner, 2002) ${ }^{13}$. Así se narren lindezas o tragedias, hay materia de continuidad de

${ }^{10}$ En Los orígenes del totalitarismo, Hannan Arendt señala: "Cualesquiera que hable o escriba acerca de los campos de concentración es considerado como un sospechoso; y si quien habla ha regresado decididamente al mundo de los vivos, él mismo se siente asaltado por dudas con respecto a su verdadera sinceridad, como si hubiese confundido una pesadilla con la realidad" (en Calveiro, 2001, p. 49).

11 Después de la liberación de los sobrevivientes, y la posibilidad de narrar sus experiencias, Semprún reflexiona: "una duda me asalta sobre la posibilidad de contar. No porque la experiencia vivida sea indecible. Ha sido invivible, algo del todo diferente, como se comprende sin dificultad. Algo que no atañe a la forma de un relato posible, sino a su sustancia. No a su articulación, sino a su densidad. Sólo alcanzarán esta sustancia, esta densidad transparente, aquellos que sepan convertir su testimonio en un objeto artístico, en un espacio de creación. O de recreación. Únicamente el artificio de un relato dominado conseguirá transmitir parcialmente la verdad del testimonio. Cosa que no tiene nada de excepcional: sucede lo mismo con todas las grandes experiencias históricas" (1995, p. 25-26).

${ }^{12}$ Por su parte, Bruner (2000) señala que las historias, en tanto narrativas, toman su credibilidad de "las circunstancias en que son contadas", y así, como los actos, tienen un narrador, un escucha y una circunstancia.

${ }^{13}$ Robert Darnton sabe bien de esto: "los antropólogos relacionan los relatos con el arte de narrar los cuentos y con el contexto en el que esto se realiza" (1984, p. 21). "Como todos los narradores de cuentos, los cuentistas campesinos adaptaban el ambiente de sus cuentos a su propio medio ambiente; pero conservaban los elementos principales intactos, usando repeticiones, rimas y otros recursos nemotécnicos" (p. 22). Los propios predicadores medievales echaron mano de la tradición oral para "ilustrar sus argumentos morales", y en sus sermones entre el siglo XII al XV, "relatan las mismas narraciones que los folcloristas recogieron en las cabañas campesinas en el siglo XIX. A pesar de la oscuridad que rodea los orígenes de las novelas de caballerías, parece que una gran cantidad de literatura medieval se basaba en la tradición oral popular y no a la inversa" (p. 23); en efecto, "los cuentos pertenecían a un fondo de cultura popular que los campesinos atesoraban durante siglos con muy pocas pérdidas" (p. 23). En una gran parte de los cuentos populares "la realización de los deseos se convierte en programa de sobrevivencia, y no en fantasía para escapar de la realidad" (p. 39), y es que era tan abrumadora la realidad que, en los cuentos, no muy pocas veces los deseos cobran la forma de comida, por lo escaso de los alimentos. Ciertamente, "los cuentos están enraizdos en el mundo real"; así, su entorno es la casa y las villas por un lado, y los caminos por el otro: ese es el espacio del cuento y el lugar de vida de los campesinos de ese 
las experiencias, y en ocasiones los dolores sino se disipan o diluyen, pesan menos cuando se comunican a otros. Cuestión que saben los psicólogos, pero también los que rayaron la línea de la muerte. Dice Primo Levi que un elemento que le permitió sobrevivir en el campo de exterminio fue su voluntad de contar lo que le sucedió: "Quizá también me haya ayudado mi interés, que nunca flaqueó, por el ánimo humano y la voluntad no sólo de sobrevivir (común a todos), sino de sobrevivir con el fin preciso de relatar las cosas a las que habíamos asistido y que habíamos soportado" (1958, p. 211). En esa misma tesitura, pero desde Latinoamérica, Juan Gelman reflexiona: "Es singular que sean los sobrevivientes de los campos las víctimas que más ahondan en lo que aconteció. Salen así del lugar de víctima que quiso imponerles para siempre la dictadura militar y sólo ellas saben a qué costo. Su contribución al despeje de la verdad y la memoria cívica es inestimable" para distintas sociedades (2002, p. 13). Con diversas obras, advierte el mismo escritor, se intenta acabar con "el silencio que navega sobre la amnesia"; lo cual quiere decir que la amnesia, la desmemoria, el olvido, se edifican con el silencio, la antítesis de la comunicación. Se entiende, en consecuencia, lo que escribe Todorov: "Los muertos demandan a los vivos: recordadlo todo y contadlo; no solamente para combatir los campos sino también para que nuestra vida, al dejar de sí una huella, conserve su sentido" (en Calveiro, 2001, p. 37).

\section{Edificación narrativa de la memoria: la retórica}

Las narraciones, en todo caso, son también formas de la retórica (Billig, 1986; Shotter, 1990), son fórmulas para la construcción de memorias y olvidos en las sociedades y hay que reconocerlas así. Lo que Goodman sostiene, en el sentido de que: "en una obra literaria lo que normalmente cuenta no es únicamente la historia que se cuenta, sino cómo se cuenta" (en Páez, Igartua y Adrián, 1997, p. 143), opera igualmente para las narraciones que sobre el pasado hacemos. Ciertamente, no se trata de contar más, sino también de contar mejor (Vázquez, 2001) ${ }^{14}$, cosa que saben los distintos grupos marginales que durante mucho tiempo han relatado acontecimientos que grupos de poder se han negado a reconocer, porque la versión que se ha impuesto sobre determinados sucesos del pasado se ha manejado como verdad. Si una versión, una visión o una interpretación en torno al pasado se institucionaliza, termina por traducirse en "un referente de verdad"; en efecto, existe una estructura retórica en las instituciones, una forma pautada en la utilización del lenguaje: cuando se ha usado, se hace referencia a él, se recuerda y se mantiene como parte de lo que 'todo el mundo sabe'" (Schudson, en Vázquez, 2001, p. 129). Lo cual puede advertirse en cualquier esfera de poder, sean instituciones académicas, eclesiásticas o gobiernos: dictaminan qué debe ser conservado y hablado, y qué ocultado, callado y omitido. Los gobiernos dictatoriales y totalitarios son muy dados a extremar esas prácticas.

entonces. Son en origen narraciones populares, por ejemplo de campesinos, que dan cuenta de su propia existencia; después, las nodrizas y las sirvientas se convierten en puentes entre la cultura del pueblo y la de élite. Ellas le narran los cuentos a los hijos de los ricos y de ahí pasan a la escritura. No sin cambios.

14 "Contar bien significa: de manera que sea escuchado. No lo conseguiremos sin algo de artificio. ¡El artificio suficiente para que se vuelva arte!” (Semprún, 1995, p. 140). 
Los intereses y propósitos, en este sentido, juegan un papel relevante. Lingüísticamente han de construirse cantidad de discursos en torno al pasado, y por eso mismo la manera como se exponen ciertos relatos no es neutra, al contrario, está intrínsecamente relacionada con el contexto en el que surge y se utiliza, tal como lo advierte Gergen (1994, p. 253): "la multiplicidad narrativa es importante primeramente a causa de sus consecuencias sociales, la multiplicidad se ve favorecida por la variada gama de relaciones en las que las personas están enredadas y las diferentes demandas de contextos relacionales diversos"15. Y exactamente lo contrario de la multiplicidad, la univocidad, es lo que se ha desplegado en sociedades sitiadas por el discurso y las prácticas totalitarias, que terminan por narrar historias inverosímiles que se imponen con presión y hasta con balas, pero que al paso del tiempo se van desdibujando, como el jabón y el agua hacen con las pintas cubiertas en los muros.

Pero hay otros que permanecen, son más duraderos, como la narrativa que dibuja a las brujas, esas que al arribo de los siglos XV y XVI son desplazadas por un discurso filosófico y una práctica médica que tienden a distanciarse de las viejas formas y de los discursos mágicos y hechiceros para justificarse. Emplean un nuevo lenguaje, el empuje de la incipiente modernidad así se los demanda. Las practicantes de la magia natural serán no sólo excluidas sino objeto de exterminio, y en ello la retórica juega un papel primordial. En efecto, "el lenguaje 'menor', marginal, de la bruja, capaz de mover montañas, de volar, de curar amores infelices, será incapaz de hablar el lenguaje de las instituciones $\mathrm{y}$, por lo tanto, incapaz de defender discursivamente, ante los tribunales, una práctica milenaria por la que se le condena" (Cohen, 2003, p. 70). Y el fuego purificador será la consecuencia: más de cien mil mujeres llevadas a la hoguera entre el siglo XV y el XVI en Europa (p. 14). En este caso hay un doble juego de la retórica: por un lado, las brujas fueron incapaces de construir un relato, una retórica, que les fuera favorable ante el poder, por el otro, la retórica del poder las arrinconó en lo oscuro, en el rechazo y en el fuego, y la imagen que crearon de ellas prevalece hoy día ${ }^{16}$.

No obstante, habrá que reconocer que una buena narrativa, una buena retórica, es una buena reconstrucción, lógica, verosímil, como las expresadas por los familiares de los desaparecidos políticos de la guerra sucia en México; pero las hay también malas, como las vertidas por las versiones oficiales en torno a las cárceles clandestinas donde estuvieron esos desparecidos políticos. Oígase si no: la Secretaría de la Defensa Nacional ha dicho cantidad de veces, las que ha querido, que en las instalaciones del campo Militar Número Uno no hubo jamás preso civil alguno, es decir, que todos los detenidos en ese sitio eran militares. Pero en 1993 uno de los suyos, el general Francisco Gallardo, al encontrarse recluido en dichas instalaciones se percató de escenarios construidos para albergar, torturar y mantener a los presos políticos, lo cual echa por tierra la mala narración de los militares. Algo que la gente enterada sobre esos asuntos ya tenía muy claro ${ }^{17}$.

${ }^{15}$ Por otro lado, la narrativa "ofrece mundos alternativos que echan nueva luz sobre el mundo real" (Bruner, 2002, p. 24). Y lo realiza mediante el uso del lenguaje: traslada las posibilidades de encontrar sentido más allá de lo posible, al introducirse en otros mundos a través de la imaginación.

${ }^{16}$ La narrativa, su retórica, sirve, asimismo, para saber lo cuerdo de la gente. Los psiquiatras hacen que la gente narre historias y de acuerdo a la lógica y su corrección van marcando su sanidad (Bruner, 2002).

${ }^{17}$ Uno de los últimos prisioneros de esas celdas, pero que nada tiene que ver con la guerrilla, fue el general José Francisco Gallardo Rodríguez, quien fue recluido en 1993, y narra: "me llamaban mucho la atención los tubos con ganchos colocados al aire libre. A la gente vieja de la prisión, oficiales 
Esta edificación retórica opera no sólo en las esferas del poder, pues en la vida cotidiana también sucede: es evidente que los grupos intentan mostrar una imagen grata de su propio pasado (Baumeister y Hastings, 1998), y terminan por construir narrativas acordes para ello: nadie sensatamente se mostraría como proveniente de un pasado turbio y negro ${ }^{18}$. "Recurrimos a la demostración argumental y justificativa utilizando recursos retóricos que permiten conferir verosimilitud a nuestras declaraciones e invitan a que sean aceptadas" (Vázquez, 2001, pp. 92-93). La forma de hablar y la utilización de ciertas palabras y de otras no, de ciertos discursos en detrimento de otros es posible en un marco, en una cultura que nos antecede y que nos dota de significados para ser usados en ciertas situaciones y no en otras, y que las propias palabras y la forma de hablar ayudan a edificar; por eso se reconoce que "Una narración modela no sólo un mundo, sino también las mentes que intentan darle sus significados" (Bruner, 2002, p. 47). De ahí que se pueda señalar que las malas narrativas de amor son también en la vida diaria malas vivencias; en contraparte, las buenas narrativas de amor son en la realidad buenas vivencias, por eso arrancan sonrisas cada vez que se cuentan.

\section{Discurrimiento narrativo}

Puede advertirse que esta forma de la memoria tiene una cierta cercanía con la visión posmoderna de la historia, la que proponen autores como Hayden White, pero se asemeja en la forma, en la narrativa. Queda distante de qué temáticas trabajar, porque la memoria colectiva sigue siendo un proceso de reconstrucción de vivencias y significados de los grupos, frente a los grandes relatos ${ }^{19}$. Ahí quizá tiene más semejanzas con la historia de las mentalidades, pero no como una visión total de una época, sino la experiencia de una colectividad que se irá reconstruyendo cada vez que se narre: lo que se recuerde no siempre será lo mismo en distintos momentos. Tiene, a su vez, similitudes con la historia cultural de la que habla Peter Burke, pero en este caso la memoria no acota y alimenta a la historia, sino que deviene forma distinta del discurso en torno al pasado. Por eso es que Umberto Eco (1998, p. 184) sostiene que la "memoria colectiva se las arregla, a veces, para sobrevivir a las censuras del poder y a los silencios de la historia". Finalmente, la narrativa es una forma que adquiere la memoria colectiva, es decir, constituye el propio relato que los grupos realizan en torno a sus

adscritos como custodios desde muchos años atrás, les pregunté para qué eran esos tubos. Uno de ellos me dijo: 'No, mi general, es que ahí colgaban a la gente durante cuatro o cinco días; ahí colgaron a varios de la Liga (Comunista 23 de Septiembre)'. Alguno de ellos me contó como llegaban las ambulancias llenas de detenidos y los descargaban por la puerta lateral de la prisión" (en Veledíaz, 2004, p. 74).

18 “¿Cómo contar una historia poco creíble, cómo suscitar la imaginación de lo inimaginable si no es elaborando, trabajando la realidad, poniéndola en perspectiva? ¡Pues con un poco de artificio!" (Semprún, 1995, p. 141).

${ }^{19}$ Reconoce White (1987, p. 42): "en el ámbito de los estudios históricos, la narrativa no ha solido ser considerada ni como producto de una teoría ni como la base de un método, sino más bien como una forma de discurso que puede o no utilizarse para la representación de los acontecimientos históricos, en función de si el objetivo primario es describir una situación, analizar un proceso histórico o bien contar una historia". 
experiencias y significaciones pasadas. Importante resulta resaltar que cuando se narra no sólo se pronuncia una vivencia, pues también se ponen de manifiesto las formas que caracterizan al propio grupo, y es de esta forma narrativa que la gente del siglo XXI puede conocer lo ocurrido en centurias pasadas, en sociedades anteriores, en tiempos pretéritos. Cierto, pues con la narrativa se la da orden, estabilidad, coherencia a la experiencia, se le lleva al terreno de lo conocido, de las palabras de los signos, de la reglas, es una forma de ordenar, de dar significado a lo ocurrido en una colectividad.

Efectivamente, la narrativa, desde esta perspectiva que se ha trabajado, deviene marco social, como lo enunciaran Halbwachs y Blondel, en el sentido de que es donde se sostienen y contienen los recuerdos; punto de apoyo, porque mediante el relato se va delineando el propio recuerdo: se rememora como se narra y no a la inversa; también se advierte como esquema, tal como lo señalara Bartlett, en el sentido de configuraciones y estados interpretativos de las experiencias significativas de un pasado vivido que posibilitan que aquellas experiencias con sentido se expresen mediante ciertas estructuras en un presente o futuro próximo; y es narrativa, también, en la forma como Vygotsky lo había manifestado: la internalización de signos median la memoria permitiendo que su estructura sea una narrativa, pues se recuerda construyendo relatos, lo mismo infantes que adultos terminan por narrar lo que les ha acontecido o lo que algo significa para ellos. $Y$ en el fondo de todas estas dimensiones de la narrativa y la memoria se encuentra el sentido, lo significativo de los eventos del pasado, de lo que se conoce o puede conocerse. Y es que, en última instancia, narración remite a "saber de un modo", es decir, un modo de conocer, y un modo de conocer es un modo de narrar (Bruner, 2002), porque, ciertamente, la memoria se posibilita narrándola, porque de esa forma se transmite y la comunicación posibilita que lo comunicado se traduzca en conocimiento, lo cual es de mucha importancia, porque una sociedad que desconoce su pasado no sólo está condenada a repetirlo, y en el caso de las tragedias, como las masacres, las guerras sucias, los desaparecidos, los excesos, resulta algo ingrato, crapuloso; además puede caminar por la ruta del desconocimiento de sus presupuestos, de sus principios, y cuando se olvidan los principios se desconocen los fines, es decir, el futuro que se tenía contemplado, y entonces los proyectos se vuelven inconclusos, lo mismo en las sociedades de dos, las parejas, que en las colectividades o las sociedades grandes, como las naciones.

En contraparte, el conocimiento amplio y diverso en torno al pasado de una sociedad permite reconocer lo indeseable y educar para evitarlo, o al menos condenarlo si es indigno; pero no sólo eso, pues al acceder a una diversidad de perspectivas e interpretaciones del pasado, más allá del contraste y la discusión que se posibiliten, la univocidad o versión única se aleja, síntomas éstos de una sociedad cerrada y de gobiernos o instituciones autoritarias. Dato curioso: la memoria tiene que ver con la democracia y las libertades, cuestión de preguntarle a las personas que vivieron en los países del Este europeo y del Cono Sur en Latinoamérica; pero también tiene que ver con la identidad: cuando hay desconocimiento del pasado del que se proviene la identidad se diluye, tiende a borrase, o al menos eso es lo que se pretende con el olvido. La globalización y su neoliberalismo son conscientes de ello, cuestión de rascarle un poquito a la pretensión del gobierno foxista de eliminar de la enseñanza básica un trozo del pasado mesoamericano: un 50\% de nuestro devenir, de nuestra existencia, de nuestra cultura, de nuestra memoria, de nuestra identidad estarían desapareciendo.

La ventaja quizá radique en que en todo momento habrá formas que desafíen las narrativas únicas que se pretendan imponer, que se manifiesten en distintos momentos y lados, tiempos y espacios, 
diría Halbwachs. En los tiempos de Stalin, los rusos tenían sus palabras, como pamjat', que significa memoria y fue utilizada por la oposición para nombrar una publicación que intentaba reconstruir el pasado ruso desde otra visión, la no oficial (Todorov, 2000). En nuestro caso, México, tenemos otras tantas maneras, una entre ellas las narrativas musicales, caso concreto los corridos, considerados como un tipo de historia oral, y que resultan ser una forma de la memoria colectiva de eventos significativos dignos de relatarse, lo mismo de amores que de hazañas, de héroes que de aventuras. Los corridos, por ejemplo, dieron cuenta de un personaje que al paso del tiempo se convertiría en icono: la adelita. Antes que la historia o la literatura la considerara como sujeto de un periodo y acontecimientos, los corridos la narraron, la pusieron en escena. Hoy día tenemos otras narrativas musicales, como las de la Sonora Santanera, que se quejan: "Todo México me ha visto/calle arriba, calle abajo/por doquiera te he buscado en mi desesperación.../te busco por Guerrero, La Villa, Tizapán, por la Colonia Obrera y no te puedo hallar.../no me explico todavía el por qué tú te marchaste y un papel no me dejaste escribiendo la razón...". Efectivamente, hay razones, sentido, para buscar a alguien, pero en ocasiones no hay sentido, razones, para partir; y así, exactamente, a veces tiene sentido narrar ciertas historias, pero en otras ocasiones no.

\section{Referencias}

Bakhurst, David (1990). "La memoria social en el pensamiento soviético". En Middleton, David y Edwards, Derek (comps.). Memoria Compartida. La Naturaleza Social del Recuerdo y del Olvido, pp. 221-243. Barcelona: Paidós, 1992.

Bartlett, Frederic (1932). Remembering. A Study in Experimental and Social Psychology. Cambridge: Cambridge University Press.

Bausmeister, Roy y Hastings, Stephen (1998). "Distorsiones de la memoria colectiva: de cómo los grupos se adulan y engañan a sí mismos". En Páez, D. et al. (eds.). Memorias Colectivas de Procesos Culturales y Políticos, pp. 317-339. Bilbao: Universidad del País Vasco.

Billig, Michael (1986). Thinking and Arguing. (Conferencia inaugural pronunciada en la Loughborough University of Technology).

Blondel, Charles (1928). Introducción a la Psicología Colectiva. Buenos Aires: Troquel.

Bruner, Jerome (1990). Actos de Significado. Más Allá de la Revolución Cognitiva. Madrid: Alianza, 2000.

Bruner, Jerome (1997). La Educación Puerta de la Cultura. Madrid: Visor.

Bruner, Jerome (2002). La Fábrica de Historias. Derecho, Literatura, Vida. Buenos Aires: Fondo de Cultura Económica, 2003.

Calveiro, Pilar (2001). Desapariciones. Memoria y Desmemoria de los Campos de Concentración Argentinos. México: Taurus, 2002.

Cohen, Esther (2003). Con el Diablo en el Cuerpo. Filósofos y Brujas en el Renacimiento. México: Taurus/UNAM.

Cole, Michael (1996). Psicología Cultural. Una Disciplina del Pasado y del Futuro. Madrid: Morata. 
Corcuera, Sonia (1997). Voces y Silencios en la Historia. Siglos XIX y XX. México: Fondo de Cultura Económica, 2000.

Darnton, Robert (1984). La Gran Matanza de Gatos y otros Episodios en la Historia de la Cultura Francesa. Buenos Aires: Fondo de Cultura Económica, 1998.

Eco, Umberto (1998). "Preámbulo". En Barret-Ducrocq, Francoise (dir.), ¿Por Qué Recordar?, pp. 183-186. Barcelona: Granica, 2002.

Fernández Christlieb, Pablo (1994). La Psicología Colectiva un Fin de Siglo más Tarde. Barcelona: Anthropos/Colegio de Michoacán.

Fernández Christlieb, Pablo (2001). "La estructura mítica del pensamiento social". En Atenea Digital, $n^{\circ} 0$, abril, pp. 21. www.antalya.uab.es/athenea/num0/pablo.htm.

Fernández Christlieb, Pablo (2002). "Psicología colectiva e historia y memoria". En Flores, Fátima (coord.) Senderos del Pensamiento Social, pp. 37-52. México: Coyoacán/UNAM.

Florescano, Enrique (1987). Memoria Mexicana. México: Taurus, 2001.

Galeano, Eduardo (1986). Memoria del Fuego III. El Siglo del Viento. México: Siglo XXI, 1998.

Garrido, Manuel S. (1996). Importunar a los Muertos. México: Grijalbo.

Gelman, Juan (2002). "Preludio". En Calveiro, Pilar Desapariciones. Memoria y Desmemoria de los Campos de Concentración Argentinos, pp. 9-13. México: Taurus, 2002.

Gergen, Keneth (1994). Realidad y Relaciones. Aproximaciones a la Construcción Social. Barcelona: Paidós, 1996.

Gómez de Silva, Guido (1985). Breve Diccionario Etimológico de la Lengua Española. México: Fondo de Cultura Económica/El Colegio de México.

Halbwachs, Maurice (1925). Les Cadres Sociaux de la Mèmoire. París: PUF, 1954.

Halbwachs, Maurice (1950). La Mèmoire Collective. París, PUF, 1968.

Levi, Primo (1958). Si Esto Es un Hombre. Buenos Aires: Mila Editor, 1988.

Páez, Darío, Igartua, Juan J. y Adrián, José A. (1997). "El arte como mecanismo semiótico para la socialización de la emoción". En Páez, Darío y Blanco, Amalio (eds.) La Teoría Sociocultural y la Psicología Social Actual, pp. 131-162. Madrid: Fundación Infancia y Aprendizaje.

Ricoeur, Paul (1999a). "Definición de la memoria desde un punto de vista filosófico". En BarretDucrocq, Francoise (dir.), ¿Por Qué Recordar?, pp. 24-28. Barcelona: Granica, 2002.

Riegl, Alöis (1903). El Culto Moderno a los Monumentos. Madrid: Visor, 1987.

Shotter, John (1990). "La construcción social del recuerdo y el olvido". En Middleton, David y Edwards, Derek (comps.). Memoria Compartida. La Naturaleza Social del Recuerdo y del Olvido, pp. 137-155. Barcelona: Paidós, 1992.

Semprún, Jorge (1995). La Escritura o la Vida. Barcelona: Tusquets, 2002. 
Todorov, Tzvetan (2000). Memorias del Mal, Tentaciones del Bien. Barcelona: Península, 2002.

Vázquez, Félix (2001). La Memoria como Acción Social. Relaciones, Significados e Imaginario. Barcelona: Paidós.

Veledíaz, Juan (2004, septiembre, 26). "El hoyo sin fondo de la prisión militar". En Proceso, 1456, pp. 71-734.

Vygotsky, Lev (1930). El Desarrollo de los Procesos Psicológicos Superiores. México: Grijalbo, 1979.

Vygotsky, Lev (1931). "Desarrollo de las funciones mnemónicas y mnemotécnicas". En Lev Vygotsky Obras Escogidas, t. III, pp. 247-264. Madrid: Visor, 1995.

White, Hayden (1987). El Contenido de la Forma. Narrativa, Discurso y Representación Histórica. Barcelona: Paidós, 1992.

\section{Formato de citación}

Mendoza, J. (2004). Las formas del recuerdo. La memoria narrativa. Athenea Digital, 6. Disponible en http://antalya.uab.es/athenea/num6/mendoza.pdf

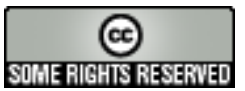

\section{Este texto está protegido por una licencia Creative Commons.}

Usted es libre de copiar, distribuir, exhibir y comunicar la obra bajo las siguientes condiciones:

Reconocimiento: Vd. debe reconocer y dar crédito al autor original.

NoComercial. Vd. no puede utilizar esta obra para fines comerciales.

NoDerivados. Vd. no puede alterar, transformar, o añadir nada a esta obra.

\section{Resumen de licencia}

$\underline{\text { Texto completo de la licencia }}$ 